\title{
In situ high-temperature Raman and FTIR spectroscopy of the phase transformation of lizardite
}

\author{
RoY TRITTSCHACK, ${ }^{1, *}$ BERNARd GrobÉTY, ${ }^{1}$ AND MONIKA KOCH-MÜLleR ${ }^{2}$ \\ ${ }^{1}$ Department of Geosciences, University of Fribourg, Chemin du Musée 6, Fribourg CH-1700, Switzerland \\ ${ }^{2}$ GeoForschungsZentrum Potsdam, Sektion 3.3, Telegrafenberg, Potsdam D-14473, Germany
}

\begin{abstract}
A temperature-dependent in situ micro-FTIR and micro-Raman spectroscopic investigation was performed on powdered (FTIR, Raman) and single-crystal (Raman) lizardite-1T samples between room temperature and $819^{\circ} \mathrm{C}$. Between room temperature and $665^{\circ} \mathrm{C}$, the $\mathrm{OH}$ stretching bands shift to lower wavenumbers, demonstrating a weak expansion of the $\mathrm{O} 3-\mathrm{H} 3 \cdots \mathrm{O} 2$ interlayer distance. Band deconvolution of FTIR and Raman spectra at room temperature show differences in the number of bands in the $\mathrm{OH}$ stretching region with respect to group theory: four (FTIR) and six (Raman) OH stretching bands, respectively. This number reduces to four (Raman) at non-ambient temperatures either caused by LO-TO splitting, the presence of non-structural $\mathrm{OH}$ species or the presence of different lizardite polytypes and/or serpentine polymorphs as well as defects. During dehydroxylation, the evolution of the integrated intensity of the $\mathrm{OH}$ bands suggests a transport of hydrogen and oxygen as individual ions/molecule or $\mathrm{OH}^{-}$. A significant change in Raman spectra occurs between 639 and $665{ }^{\circ} \mathrm{C}$ with most lizardite peaks disappearing contemporaneously with the appearance of forsterite-related features and new, non-forsterite bands at 183, 350, and $670 \mathrm{~cm}^{-1}$. A further band appears at $1000 \mathrm{~cm}^{-1}$ at 690 ${ }^{\circ} \mathrm{C}$. The long stability of Si-O-related bands indicates a delayed decomposition of the tetrahedral sheet with respect to the dehydroxylation of the octahedral sheet. Moreover, evidence for a small change in the ditrigonal distortion angle during heating is given. In general, all appearing non-forsterite-related frequencies are similar to Raman data of talc and this indicates the presence of a talc-like intermediate.
\end{abstract}

Keywords: Lizardite, dehydroxylation, Raman, and FTIR spectroscopy, talc-like intermediate

\section{INTRODUCTION}

Lizardite $\mathrm{Mg}_{3} \mathrm{Si}_{2} \mathrm{O}_{5}(\mathrm{OH})_{4}$ is a member of the serpentine group. The 1:1 phyllosilicate consists of brucite-like octahedral sheets connected to $\mathrm{SiO}_{4}$ tetrahedral sheets. The most common structures are the one-layer $1 T$ and the two-layer $2 H_{1}$ polytypes, although other polytypes are known. At ambient pressure and temperatures above $500{ }^{\circ} \mathrm{C}$, lizardite breaks down to anhydrous phases, i.e., forsterite and enstatite. A probable mechanism for the liberation of the hydroxyl groups is a reaction of two adjacent hydroxyl groups that presumably recombine to a water molecule (e.g., Guggenheim et al. 1987). Theoretical studies have shown that the two symmetrically distinguishable hydroxyl groups (Fig. 1) in each lizardite polytype can be recognized by their infrared (IR) and Raman active bands in the frequency range between 3500 and $3800 \mathrm{~cm}^{-1}$ (Balan et al. 2002; Auzende et al. 2004). Temperature-dependent FTIR and Raman studies are therefore suitable to study the structural change of serpentine minerals, which is difficult to understand by X-ray techniques (XRD) alone (e.g., Guggenheim and Zhan 1998). In general, temperaturedependent peak shifts or intensity/absorbance changes are caused by changes in the bond length, symmetry changes, or short- to large-scaled structural rearrangements (e.g., Zhang et al. 2006; Gillet 1996). Intensity changes of the OH Raman bands

\footnotetext{
*E-mail: roy.trittschack@unifr.ch
}

and changes in absorbance of the OH IR bands can serve as a (semi-)quantitative information source to estimate the amount of $\mathrm{OH}$ or $\mathrm{H}_{2} \mathrm{O}$ within the crystal structure. Previous Raman and FTIR studies on serpentine minerals were mainly used as tools to distinguish serpentine polymorphs (e.g., Rinaudo et al. 2003) or to determine the structural behavior at high-pressure/hightemperature (HP/HT) conditions within the stability region of

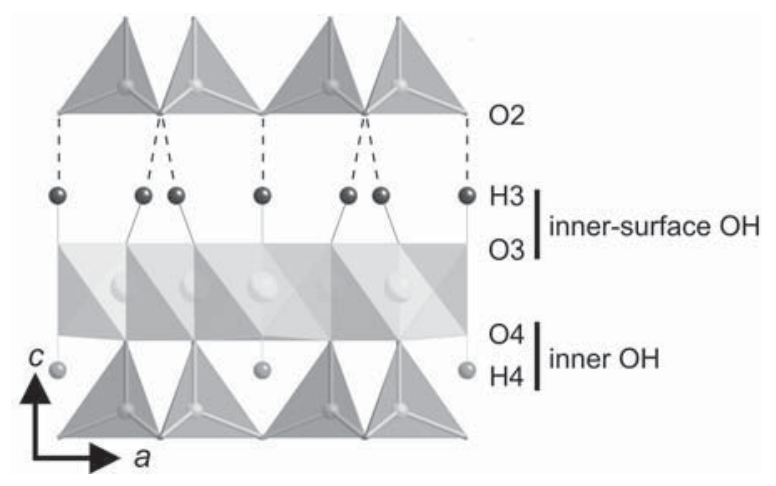

FIGURE 1. Crystal structure of lizardite-1T (Mellini 1982) projected along the $b$ axis showing the positions of the inner and inner-surface hydroxyl groups. Some authors, e.g., Auzende et al. (2004), designate the "inner-surface" $\mathrm{OH}$ also as "outer" $\mathrm{OH}$. 
lizardite (Auzende et al. 2004). To our knowledge, the ambientpressure breakdown of serpentine minerals to forsterite via an intermediate phase has not yet been studied by in situ HT Raman and HT FTIR techniques. This study focuses on in situ Raman and FTIR spectroscopy of a well-characterized lizardite-1T from room temperature (RT) to $819{ }^{\circ} \mathrm{C}$, i.e., well above the thermal breakdown interval (Trittschack and Grobéty 2012).

\section{EXPERIMENTAL METHODS}

\section{Sample material}

The investigated lizardite sample, for which no origin is given, was taken from the ETH Zurich mineral collection. The electron microprobe-based determination of the stoichiometry yields $\left(\mathrm{Mg}_{2.84} \mathrm{Fe}_{0.04} \mathrm{Al}_{0.03}\right)\left(\mathrm{Si}_{2.02}\right) \mathrm{O}_{5}(\mathrm{OH})_{4.09}$ and a total water content of $13.3 \mathrm{wt} \%$, which was estimated by thermogravimetry. The sample mainly consists of the $1 T$ polytype, although there are intergrowths of curled 1:1-layers and regions with a high concentration of stacking faults based on transmission electron microscopy (TEM) analyses (Trittschack and Grobéty 2012).

As reference, a lizardite- $1 T$ single crystal from the Monte Fico quarries, Elba Island/Italy, was used (private collection, Marcello Mellini). Comprehensive mineralogical and chemical data of this sample are provided by Mellini and Viti (1994) and Fuchs et al. (1998).

Powdered lizardite was gently pressed in a diamond-anvil cell (DAC) without gasket until a transparent film was generated. Single transparent pieces of this film were deposited in a sapphire crucible and used for all FTIR in situ dehydroxylation experiments. Raman experiments were performed on powdered samples and a Monte Fico single crystal, placed into a sapphire crucible.

\section{FTIR and Raman spectroscopy}

FTIR measurements were performed with a Bruker VERTEX 80v spectrometer attached to a Hyperion1000 IR microscope and a software-controlled Linkam TS1000 heating stage at the GeoForschungsZentrum Potsdam (GFZ Potsdam/ Germany). Spectra were collected in the $2500-4000 \mathrm{~cm}^{-1}$ frequency range using a LN-INSB D413 detector, a KBr beamsplitter, and a $6 \mathrm{~mm}$ aperture in transmission mode. Single spectra were measured with a resolution of $2 \mathrm{~cm}^{-1}$ and averaged over 60 individual scans which results in a measurement interval of about $64 \mathrm{~s}$. A $20 \times 20 \mu \mathrm{m}$ sized area without visible cracks was chosen to collect FTIR spectra of the lizardite thin films. A constant flow of nitrogen was utilized to guarantee a rapid removal of the water generated during the dehydration. The thermocouple was calibrated using the melting points of different salts: $\mathrm{NaNO}_{3}\left(T_{\mathrm{M}}=306^{\circ} \mathrm{C}\right)$, $\mathrm{NaI}\left(T_{\mathrm{M}}=651^{\circ} \mathrm{C}\right)$, and $\mathrm{NaCl}\left(T_{\mathrm{M}}=801{ }^{\circ} \mathrm{C}\right)$. The $0{ }^{\circ} \mathrm{C}$ point was included in the calibration line.

Micro-Raman investigations were performed with a HORIBA HR 800 UV spectrometer equipped with an Olympus BX41 microscope (20x objective) in backscattering configuration at the GFZ Potsdam. All examined spectra were measured with an argon laser $(488 \mathrm{~nm}, 300 \mathrm{~mW})$. The spectrometer was calibrated against the emission bands of a neon lamp. Spectra acquisition time was $10 \mathrm{~s}$ and 4 spectra were cumulated for each temperature step. In general, spectra were measured in the frequency ranges of $100-1200$ and $3500-3800 \mathrm{~cm}^{-1}$.

Non-isothermal runs were monitored to study the dehydroxylation of lizardite. The Raman experiments were obtained between 21 and $819^{\circ} \mathrm{C}$. An initial heating rate of $130{ }^{\circ} \mathrm{C} / \mathrm{min}$ was used to heat the sample from 21 to $253^{\circ} \mathrm{C}$, afterward the heating rate was fixed to $100^{\circ} \mathrm{C} / \mathrm{min}$ for $50^{\circ} \mathrm{C}$ increments (to $459^{\circ} \mathrm{C}$ ) and $50^{\circ} \mathrm{C} /$ min for $25^{\circ} \mathrm{C}$ increments, starting with the $484^{\circ} \mathrm{C}$ spectrum and ending with the $819^{\circ} \mathrm{C}$ spectrum. Single measurements after each temperature increment required 5 min owing to the Raman setup conditions. The FTIR data were collected between 21 and $665{ }^{\circ} \mathrm{C}$. Initially, a heating rate of $100{ }^{\circ} \mathrm{C} / \mathrm{min}$ was used for the following temperature intervals: 21-98, 98-201, 201-304, 304-356, 356-407, 407-433, and $433-459^{\circ} \mathrm{C}$. FTIR spectra were recorded after each temperature interval. A linear heating rate of $1{ }^{\circ} \mathrm{C} / \mathrm{min}$ and a continuous measurement was chosen from 459 to $665^{\circ} \mathrm{C}$.

\section{Fitting procedure}

Peak deconvolution and integration were performed with the PeakFit software package. The low-frequency range (100-1200 $\left.\mathrm{cm}^{-1}\right)$ and high-frequency range (3500-3800 $\mathrm{cm}^{-1}$ ) were treated independently. The Savitzky-Golay algorithm was used to smooth single spectra. After baseline subtraction, all spectra were deconvoluted using a combined Gaussian-Lorentzian Amp function for which the width at the base and the full-width at half maximum (FWHM) are refinable parameters. A minimum number of peaks was chosen to guarantee a best fit to allow the comparison between individual time and temperature resolved spectra as shown by Auzende et al. (2004).

\section{RESULTS}

\section{Raman and FTIR spectra at ambient conditions}

The low-frequency range of the Raman spectra obtained at RT is characterized by five well-resolved strong bands that are accompanied by six weak bands (Fig. 2). Additional bands (Table 1) observable in the deconvoluted lizardite-1T spectrum of the Monte Fico sample are very weak or not present in spectra obtained from the powdered sample (Fig. 2). Precise peak positions and band assignments of both lizardite samples are summarized in Table 1. In general, the positions of the main peaks in the low-frequency range are identical with data summarized by Rinaudo et al. (2003). However, some bands were assigned to chrysotile by the latter (Table 1). We cannot unambiguously distinguish between purely lizardite-related or chrysotile containing, because these bands occur in the Monte Fico lizardite sample also, which contains up to $25 \mathrm{wt} \%$ chrysotile (Viti 2010). The $510 \mathrm{~cm}^{-1}$ band assigned to deformation vibrations of $\mathrm{SiO}_{4}-\mathrm{AlO}_{4}$ tetrahedra is visible in the spectrum of the Monte Fico crystal,

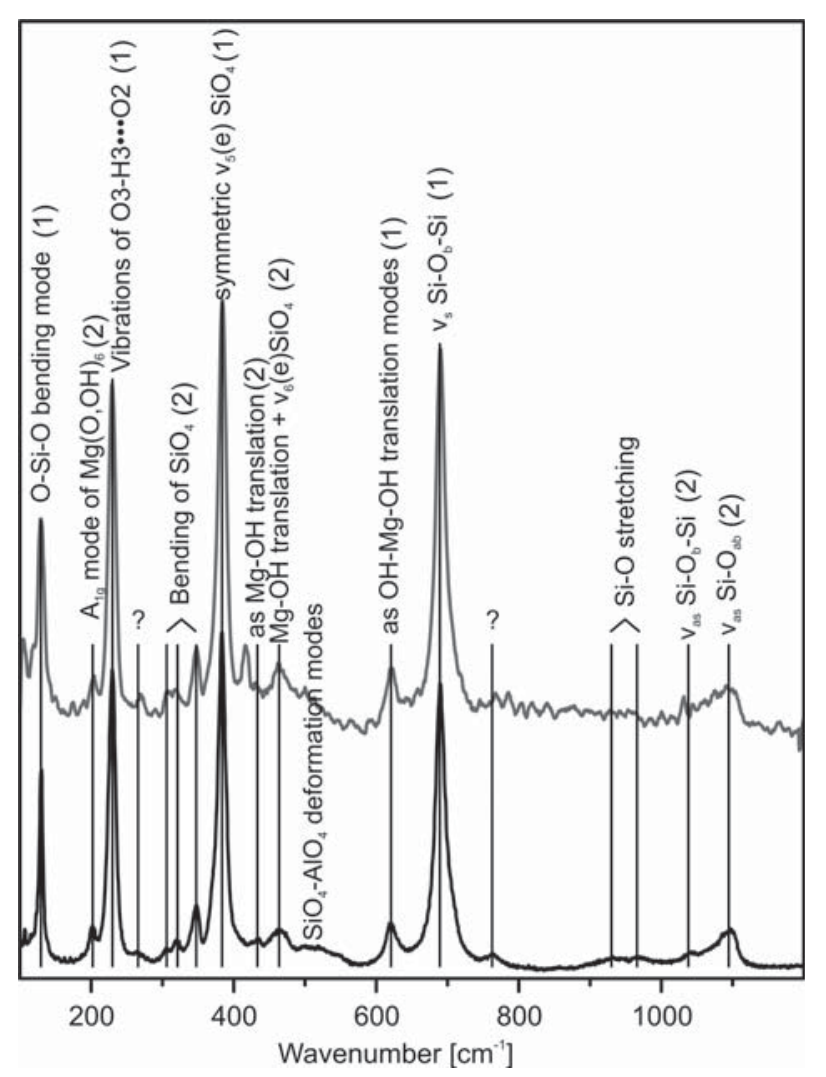

FIGURE 2. RT Raman spectra of lizardite-1T; the upper spectrum corresponds to the powdered ETH Zurich sample LizZH1, the lower spectrum to the single-crystal lizardite-1T, Monte Fico quarry (Elba, Italy); (1) indicates the five major bands and (2) the six minor bands of lizardite. 
TABLE 1. Lizardite-1T related Raman and FTIR bands and their assignments at room temperature

\begin{tabular}{|c|c|c|c|}
\hline$\overline{\text { Band assignment }{ }^{*}, \dagger}$ & 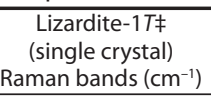 & $\begin{array}{c}\text { Lizardite-1T } \\
\text { Raman bands } \\
\left(\mathrm{cm}^{-1}\right)\end{array}$ & $\begin{array}{c}\text { Lizardite-1T } \\
\text { FTIR bands } \\
\left(\mathrm{cm}^{-1}\right)\end{array}$ \\
\hline Unknown & & 117.1 & \\
\hline O-Si-O bending mode (1) & 129.4 & 129.5 & \\
\hline $\mathrm{A}_{1 \mathrm{~g}}$ mode of $\mathrm{Mg}(\mathrm{O}, \mathrm{OH})_{6}$ & 201.9 & 202.4 & \\
\hline Vibrations of $\mathrm{O} 3-\mathrm{H} 3 \cdots \mathrm{O} 2$ (1) & 229.1 & 229.4 & \\
\hline Unknown & & 265.7 & \\
\hline \multirow[t]{2}{*}{ Bending of $\mathrm{SiO}_{4}$} & $\begin{array}{l}305.1 \\
320.0\end{array}$ & & \\
\hline & 346.2 & 349.1 & \\
\hline s Mg-OH vibration ${ }^{\mathrm{chr}}$ & 371.4 & & \\
\hline $\mathrm{S} \mathrm{V}_{5}(\mathrm{e})$ bending of $\mathrm{SiO}_{4}(1)$ & 383.5 & 384.1 & \\
\hline Unknown artifact & & 416.9 & \\
\hline $\begin{array}{l}\text { as } \mathrm{Mg}-\mathrm{OH} \text { translation }{ }^{\mathrm{chr}} \\
\mathrm{Mg}-\mathrm{OH} \text { translation }+\end{array}$ & $\begin{array}{l}430.4 \\
464.5\end{array}$ & 465.7 & \\
\hline $\mathrm{SiO}_{4}-\mathrm{AlO}_{4}$ deformation mode & 517.5 & & \\
\hline $\begin{array}{l}\text { as } \mathrm{OH}-\mathrm{Mg}-\mathrm{OH} \text { translation } \\
\text { mode (1) }\end{array}$ & 621.6 & 621.6 & \\
\hline Unknown & 669.9 & & \\
\hline $\begin{array}{l}\text { s Si- } \mathrm{O}_{\mathrm{b}} \text {-Si bridging/ } \\
\text { stretching mode (1) }\end{array}$ & 689.8 & 690.1 & \\
\hline $\begin{array}{l}\text { Mg-OH outer s } \\
\text { translation mode }\end{array}$ & 707.1 & & \\
\hline Unknown & 763.4 & & \\
\hline \multirow[t]{2}{*}{ Si-O stretching mode } & 928.6 & & \\
\hline & 972.4 & & \\
\hline as $\mathrm{Si}-\mathrm{O}_{b}-\mathrm{Si}$ stretching mode & 1050.2 & 1072.4 & \\
\hline as $\mathrm{Si}-\mathrm{O}_{\mathrm{nb}}$ stretching mode & 1094.3 & 1099.1 & \\
\hline \multirow[t]{6}{*}{$\mathrm{OH}$ stretching frequencies } & 3653.2 & 3649.4 & 3652 \\
\hline & 3667.4 & 3670.2 & 3669 \\
\hline & 3672.8 & 3684.0 & 3688 \\
\hline & 3683.6 & 3690.6 & 3703 \\
\hline & 3693.7 & 3698.1 & \\
\hline & 3702.7 & 3704.0 & \\
\hline
\end{tabular}

Notes: as = antisymmetric, $\mathrm{s}=$ symmetric, $\mathrm{chr}=$ attributed to chrysotile vibration by Rinaudo et al. (2003). (1) Indicates the five major Raman bands of lizardite in the low-frequency range.

* Rinaudo et al. (2003).

† Farmer (1974).

₹ Sample described by Mellini and Viti (1994), but measured individually for this study.

but is missing in the powdered sample due to the low-Al content of our sample. The antisymmetric Si-O stretching frequencies centered at around 1072 and $1099 \mathrm{~cm}^{-1}$ are present but an accurate fitting in the in situ recorded spectra is difficult owing to their low intensity and large FWHM (Fig. 2).

For a deconvolution of the overlapping $\mathrm{OH}$ stretching frequencies at RT, four peaks were used for the FTIR spectra (Fig. 3a) and six for the related Raman spectra (Fig. 3b). Six bands were required also to fit $\mathrm{OH}$ bands in the Raman spectrum obtained from the Monte Fico single crystal (Table 1). This amount of bands is not compatible with theoretical data of the serpentine polymorph chrysotile by Kloprogge et al. (1999), who indicated the presence of just four Raman active $\mathrm{OH}$ stretching frequencies. Generally, the band assignments (Figs. 3a-3b) follow the scheme of Balan et al. (2002), whereas close-set bands are interpreted as originating from the same mode. Regarding the band multiplication, the possible role of longitudinal optical and transversal optical splitting modes and multiple $\mathrm{OH}$ bands originating from different polytypes/polymorphes will be discussed in section "OH bands and their assignments." An increased number of $\mathrm{OH}$ stretching frequencies in the Raman spectra, compared to the group theory predictions, were reported by Auzende et al. (2004).

\section{Temperature-dependent Raman spectra in the low- frequency region}

For an investigation of the phase transformation behavior, six peaks of the RT spectra of the powdered sample were monitored through the entire temperature range. Smaller peaks, present in the RT spectrum, were omitted owing to the high background at elevated temperatures (Fig. 4). In general, the intensity of all lizardite-related bands decreases with increasing temperature and a steady frequency shift to lower wavenumbers is observed (Figs. 4, 5, and 6). Most shifts are linear functions of temperature, except for the $\mathrm{A}_{1 \mathrm{~g}}$ mode of the $\mathrm{Mg}(\mathrm{O}, \mathrm{OH})_{6}$ group and the symmetrical $\mathrm{Si}-\mathrm{O}_{\mathrm{b}}-\mathrm{Si}$ vibration (Figs. $6 \mathrm{~b}$ and $6 \mathrm{f}$ ). There is no fundamental modification in the Raman pattern of the powdered sample taken at temperatures up to $639^{\circ} \mathrm{C}$ (Figs. 4 and 5b). A significant change is observed between the Raman spectrum at 639 and $665^{\circ} \mathrm{C}$ (Figs. 5b-5c). In the latter, most lizardite-related bands suffer an intensity decrease. In the spectrum of $639^{\circ} \mathrm{C}$, the formation of forsterite is documented with a broad band at around $848 \mathrm{~cm}^{-1}$ (Fig. 5b). Initially, this band can be fitted adequately by one single peak. With increasing temperature, this broad band is split into two bands centered at 810 and 844 $\mathrm{cm}^{-1}$ (Fig. 5c). Both are attributed to Si-O stretching vibrations (McKeown et al. 2010). The same bands are also present in a quenched sample, but shifted to $822 \mathrm{~cm}^{-1}\left(v_{1}\right)$ and $855 \mathrm{~cm}^{-1}\left(v_{3}\right)$ (Fig. 5f). Together with bands assigned to forsterite, a new peak at around $183 \mathrm{~cm}^{-1}$ appears (gray shaded area in Fig. 4, marked by a rhomb in Figs. 5b-5d). This band rapidly looses intensity at higher temperatures, which is in contrast to forsterite bands, which gain intensity. Simultaneously, a significant reduction in intensity and a frequency jump is observable for the $v_{\mathrm{s}} \mathrm{Si}-\mathrm{O}_{\mathrm{b}}-\mathrm{Si}$ lizardite vibration (Fig. 6f). An additional feature appearing in the $665^{\circ} \mathrm{C}$ spectrum is a $350 \mathrm{~cm}^{-1}$ band and a band at $1000 \mathrm{~cm}^{-1}$ at $690^{\circ} \mathrm{C}$ (Figs. 5c-5d). Only the latter persists up to $819^{\circ} \mathrm{C}$ and is also present in spectra of the quenched sample (Fig. 5f). The various $\mathrm{O}-\mathrm{Si}-\mathrm{O}$ and $\mathrm{SiO}_{4}$-related lizardite stretching vibrations in the low-frequency range (Fig. 2, Table 1) and the $223 \mathrm{~cm}^{-1}$ ( $v=229 \mathrm{~cm}^{-1}$ at RT) band, characteristic for O3-H3 $\cdots$ O2 group vibrations (Fig. 1, Rinaudo et al. 2003), are present until the initial appearance of forsterite.

\section{Temperature-dependent Raman- and FTIR-spectra in the $\mathrm{OH}$ stretching region}

At temperatures higher than RT, the number of peaks necessary to deconvolute the $\mathrm{OH}$ bands adequately is four, both for the Raman (Fig. 7) and IR spectra (Fig. 8). There are no additional $\mathrm{OH}$-related bands visible during heating. The frequency shifts of the four bands attributed to $\mathrm{OH}$ are illustrated in Figure 9 (FTIR data) and Figure 10 (Raman data) as a function of temperature. Following Balan et al. (2002), three bands (Fig. 3) are attributed to the out-of-phase stretching modes of the inner-surface $\mathrm{OH}$ groups $\left(3652 \mathrm{~cm}^{-1}\right)$, the in-phase stretching modes of the innersurface $\mathrm{OH}$ groups $\left(3688 \mathrm{~cm}^{-1}\right)$ and the stretching modes of the inner $\mathrm{OH}$ groups $\left(3703 \mathrm{~cm}^{-1}\right)$. The fourth deconvoluted band at $3669 \mathrm{~cm}^{-1}$ (RT) is not indicated among the 51 transverse optical modes indicated by Balan et al. (2002). The in-phase stretching modes of the inner-surface $\mathrm{OH}$ groups and the stretching vibrations of the inner $\mathrm{OH}$ groups show a linear temperature relationship, whereas two linear segments are necessary to describe the 


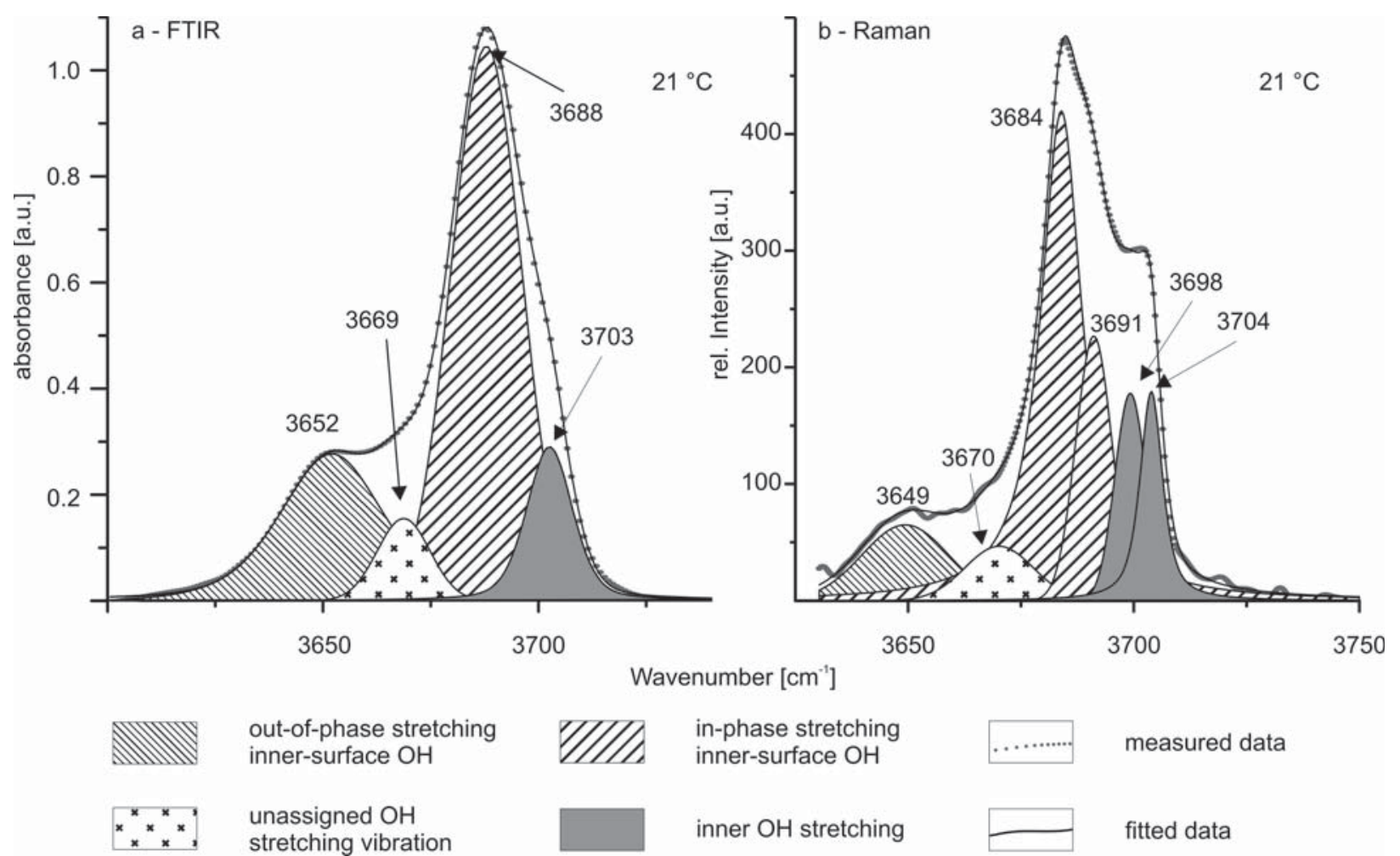

FIGURE 3. FTIR (a) and Raman (b) signals of the OH stretching region illustrating the peaks used for a signal deconvolution at RT.

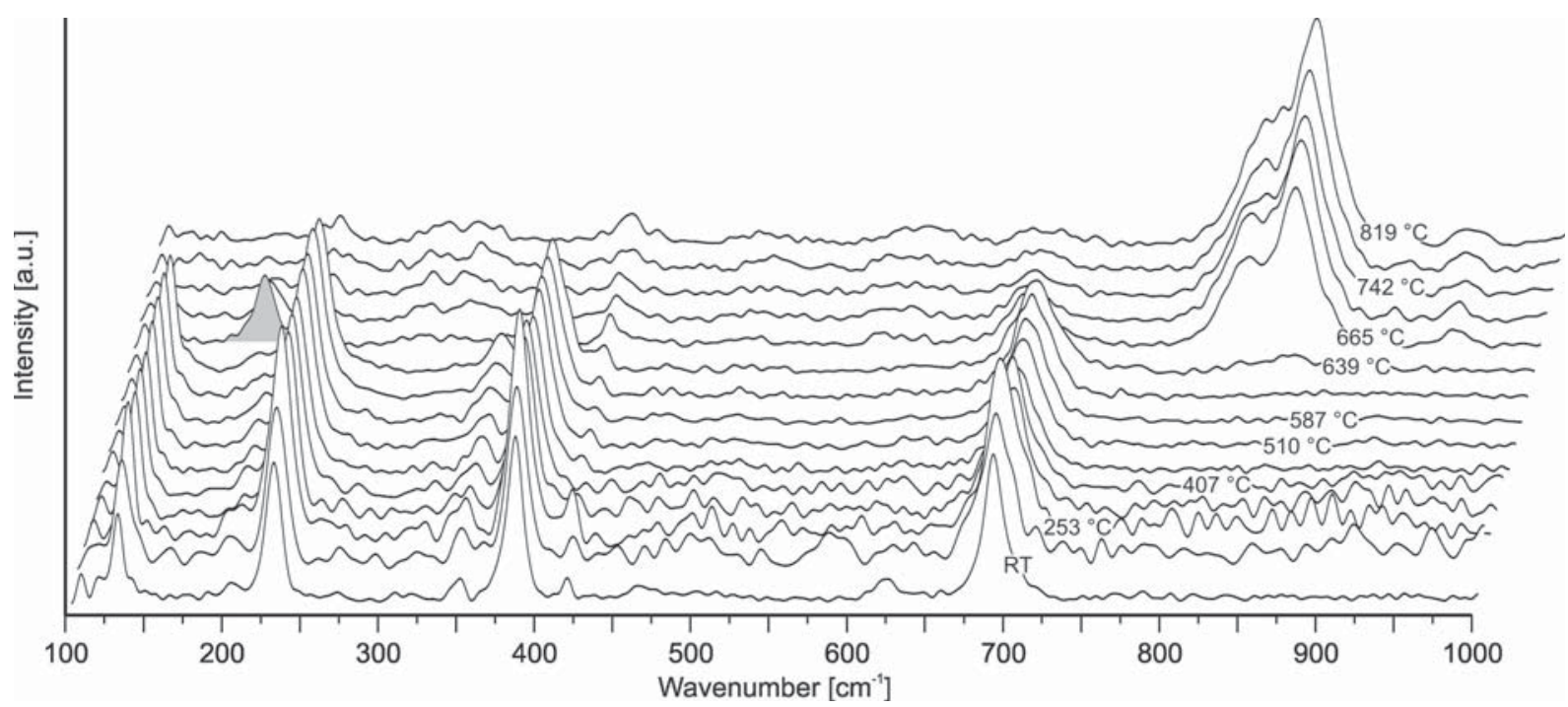

FIGURE 4. Temperature-dependent phase transformation behavior of the low-frequency Raman bands of lizardite-1T between RT and $819{ }^{\circ} \mathrm{C}$; gray shading marks the high-temperature $183 \mathrm{~cm}^{-1}$ band at $665{ }^{\circ} \mathrm{C}$ simultaneously with a forsterite doublet between 800 and $900 \mathrm{~cm}^{-1}$.

thermal frequency evolution of the out-of-phase vibration of the inner-surface $\mathrm{OH}$ groups. The temperature at the intersection of the segments is indicated by an arrow in Figure 9a. This temperature coincides approximately with the temperature of an accelerated dehydroxylation behavior (Fig. 11a). The unassigned band shows a similar non-linear frequency evolution (Fig. 9b).
The frequency of all Raman $\mathrm{OH}$ vibration modes decreases linearly with temperature (Fig. 10). A frequency jump in Raman data, characterized by an obvious deviation from the linear course and marked by the last two data points per Raman band, occurs between 639 and $665^{\circ} \mathrm{C}$. The latter spectrum is the last in which $\mathrm{OH}$ bands are still visible. 
Libowitzky (1999) showed that the OH stretching frequencies can be used to calculate $\mathrm{O} \cdots \mathrm{O}$ and $\mathrm{H} \cdots \mathrm{O}$ distances in hydrous minerals, i.e., the lizardite interlayer distances (for comparison see Guggenheim and Zhan 1998) are determined from the $\mathrm{OH}$ stretching frequencies. Using this method, the interlayer distance (O2-O3 distance) derived from the FTIR data increases from $2.89 \pm 0.06 \AA$ at RT to $2.90 \pm 0.06 \AA$ at $582^{\circ} \mathrm{C}$. These distances correspond to an $\mathrm{O} 2 \cdots \mathrm{H} 3$ distance of $2.23 \pm 0.01 \AA$ at $\mathrm{RT}$ to 2.27 $\pm 0.01 \AA$ at $582{ }^{\circ} \mathrm{C}$.
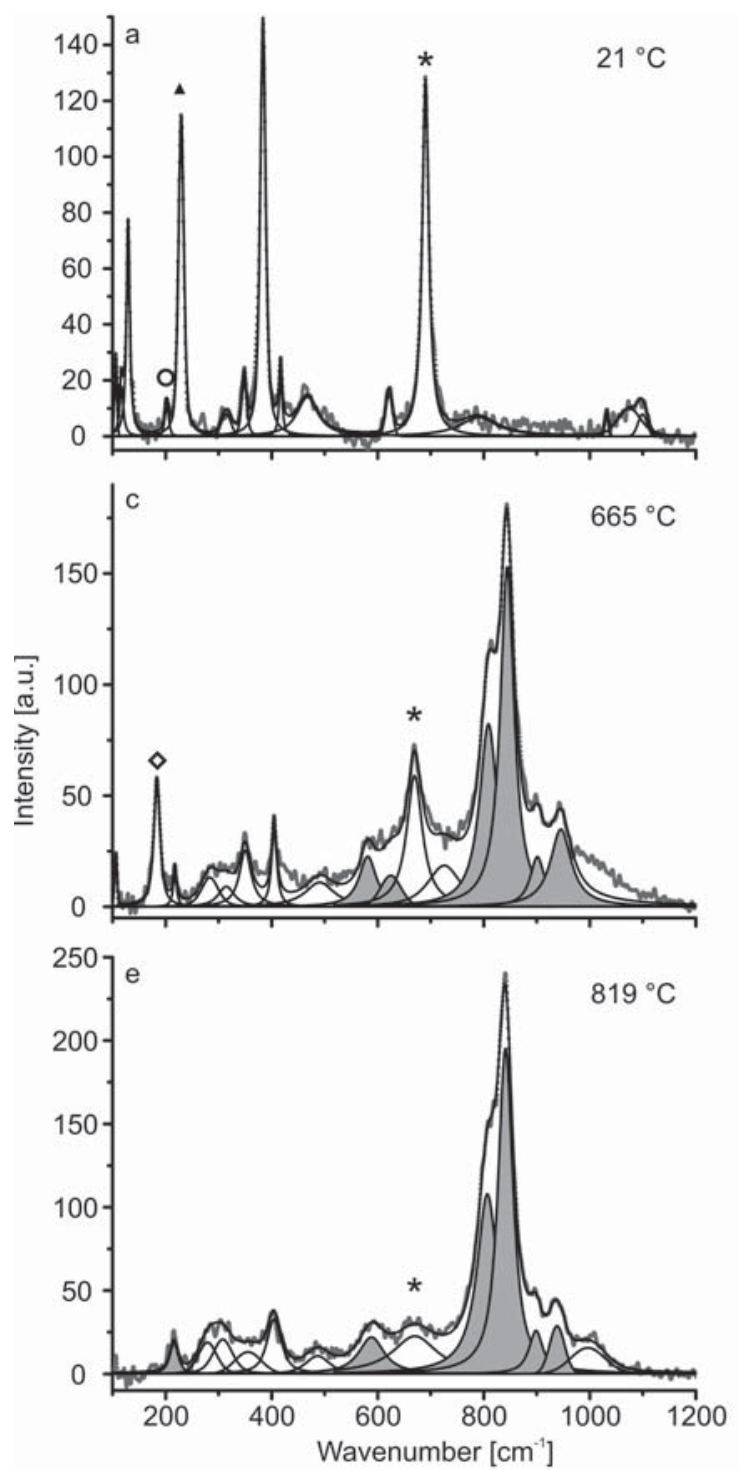

* $\quad$ v Si-O_-S $_{-}$

$\diamond \quad 183 \mathrm{~cm}^{-1}$ feature
The evolution of the integrated absorbance with increasing temperature of the four $\mathrm{OH}$ bands extracted from the in situ FTIR experiments results in a sigmoidal shaped dehydroxylation curve. Initial dehydroxylation starts at $450 \pm 20^{\circ} \mathrm{C}$. The dehydroxylation maximum lies at $540{ }^{\circ} \mathrm{C}$ (Fig. 11a). The absorbance of the individual inner-surface and inner $\mathrm{OH}$ stretching modes also starts to decrease at around $450{ }^{\circ} \mathrm{C}$ (Fig. 11b). The average intensity of the unassigned band is picking up with beginning of the dehydroxylation reaction.
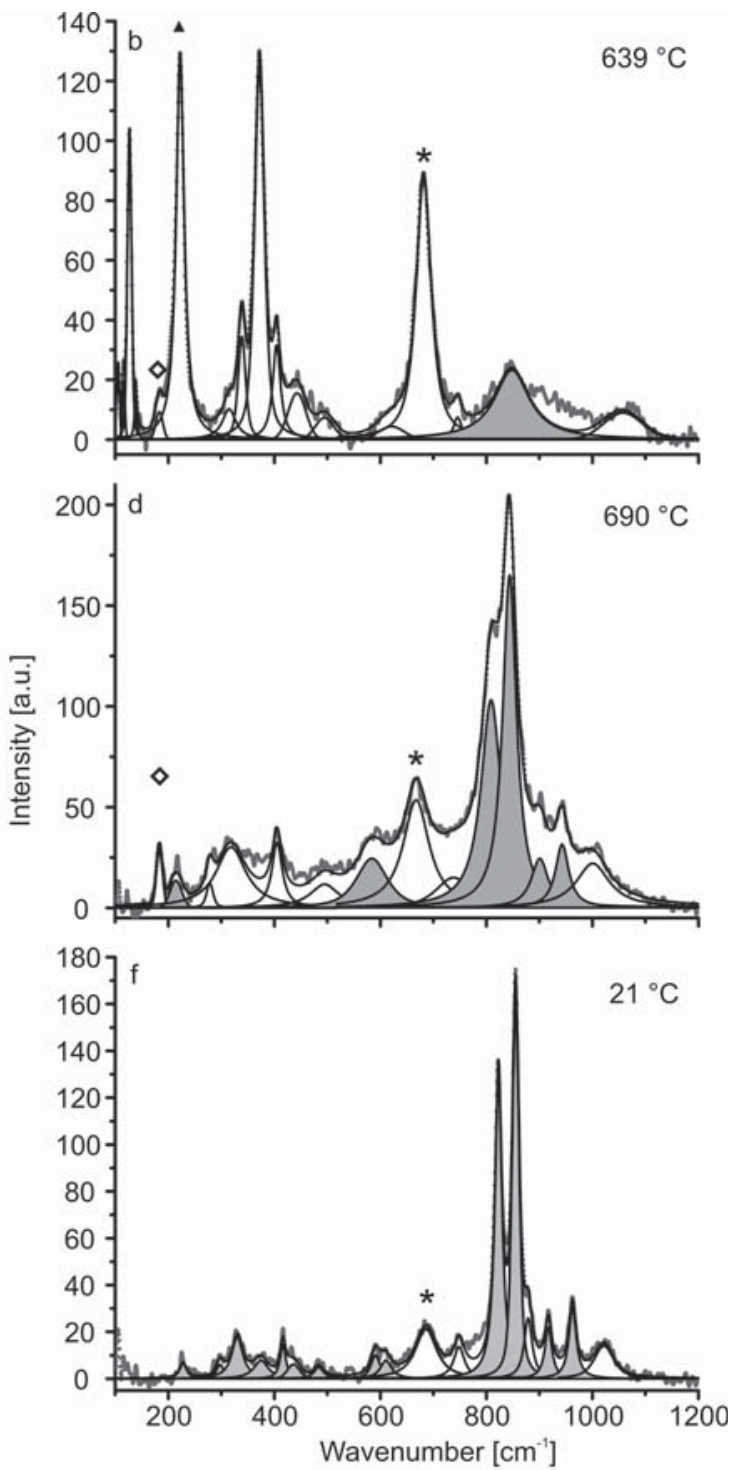

$\mathrm{O}-\mathrm{H} \cdots \mathrm{O}$ group vibrations

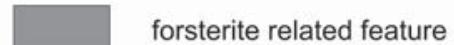

measured data

fitted data

lizardite $\mathrm{A}_{1,}$ mode of $\mathrm{Mg}(\mathrm{O}, \mathrm{OH})_{6}$

FIGURE 5. (a-f) Low-frequency range of temperature-dependent Raman measurements representing the phase transformation of lizardite-1T to forsterite; (f) sample was heated progressively to $819^{\circ} \mathrm{C}$ and afterward quenched and re-measured at RT (21 $\left.{ }^{\circ} \mathrm{C}\right)$. 

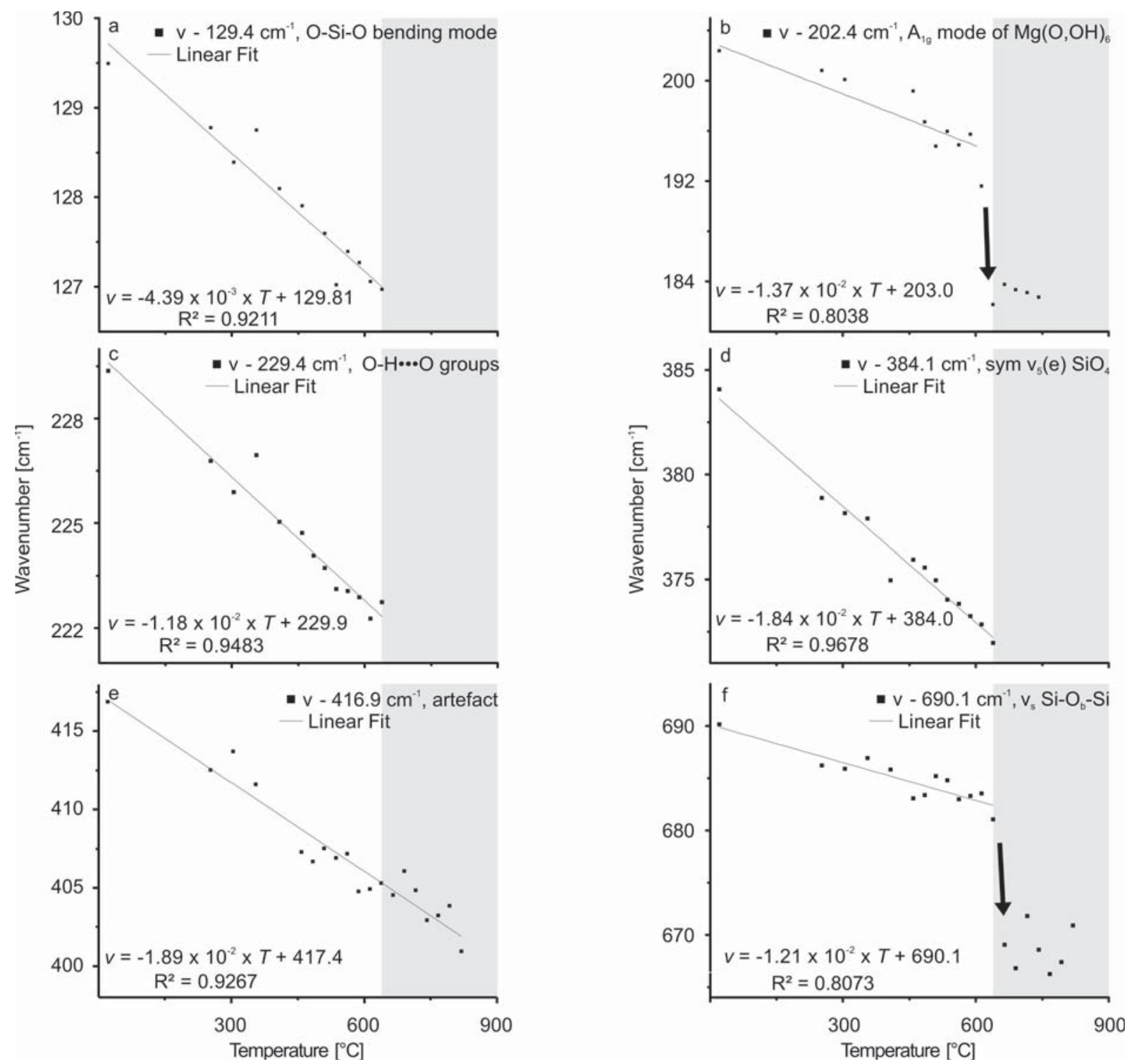

FigURE 6. (a-f) Temperature-dependent Raman band shifts in the low-frequency region of lizardite-1T; gray shading marks the presence of forsterite.

The sum curve of the four Raman $\mathrm{OH}$ stretching band intensities (including the unassigned band, for comparison see Figs. 3, 7, and 8), which occur at temperatures higher than RT, gently decreases between RT (Fig. 12a) and $450{ }^{\circ} \mathrm{C}$. The minimum of the derivative, functionally related to the maximum in the $\mathrm{OH}$ release, occurs at around $640{ }^{\circ} \mathrm{C}$. Above $665^{\circ} \mathrm{C}$ the bands disappear completely. The inner-surface $\mathrm{OH}$ stretching bands start to decrease in intensity at around 550 to $600{ }^{\circ} \mathrm{C}$ (Fig. 12b). Similar to the behavior observed in the FTIR spectra, the unassigned band has on average a higher intensity during the dehydroxylation than at lower temperatures.

\section{DISCUSSION}

\section{$\mathrm{OH}$ bands and their assignments}

Whereas RT low-frequency Raman spectra of lizardite are compatible with previous data (e.g., Rinaudo et al. 2003), OH stretching frequencies in both the Raman and FTIR data show unusual band multiplication compared to group theory considerations by Balan et al. (2002) and Prencipe et al. (2009). Additional bands to fit the spectrum for the $\mathrm{OH}$ stretching modes of lizardite at RT has been recognized previously (e.g., Auzende et al. 2004) and additional $\mathrm{OH}$ bands are also known from spectra of 2:1 phyllosilicates (Zhang et al. 2005). Three different causes are most likely responsible for the appearance of the extra $\mathrm{OH}$ band: (1) longitudinal optic-transverse optic (LO-TO) splitting, (2) additional $\mathrm{OH}$ groups such as non-structural $\mathrm{OH}$ groups, also related to disorder, and (3) mixture of lizardite polytypes and/or chrysotile-like layers. According to hybrid Hartree-Fock/Density functional theory (HF/DFT) calculations of the vibrational spectrum of lizardite, Prencipe et al. (2009) interpreted additional bands observed by Auzende et al. (2004) as originating from LOTO splitting of the three $\mathrm{OH}$ vibrational modes. Additional $\mathrm{OH}$ 
bands in Raman spectra of kaolinite are also attributed to LO-TO splitting (Farmer 1998). Prencipe et al. (2009) and Farmer (1998) comprehensively presented the physical background of such additional band appearances related to LO-TO splittings. The key parameter for LO-TO splitting is the size of individual crystals compared to the Raman laser wavelength (Farmer 1998). IR data contain mostly TO modes, except for powdered samples with crystallite sizes greater than the IR wavelength, whereas Raman data are frequently affected by LO-TO splitting (Farmer 1998). Hence, a wavelength depending behavior, i.e., band multiplication owing to sample size related parameters with respect to the IR and Raman laser wavelength, may result in additional bands in our RT FTIR and Raman data sets, with four observable IR bands, but six Raman bands. Thus, the transparent film used probably shows a less complex $\mathrm{OH}$ stretching band pattern (dominated by TO modes) than the resulting patterns of the single crystal and the loose powder used in the Raman experiments.

Non-structural $\mathrm{OH}$ species have been suggested as an alternative explanation for additional $\mathrm{OH}$ band(s) in vibrational spectra of phyllosilicates (Wang et al. 2002; Zhang et al. 2006, 2010). However, most of these bands appear during the heat treatment and before significant dehydroxylation (e.g., Zhang et al. 2010).

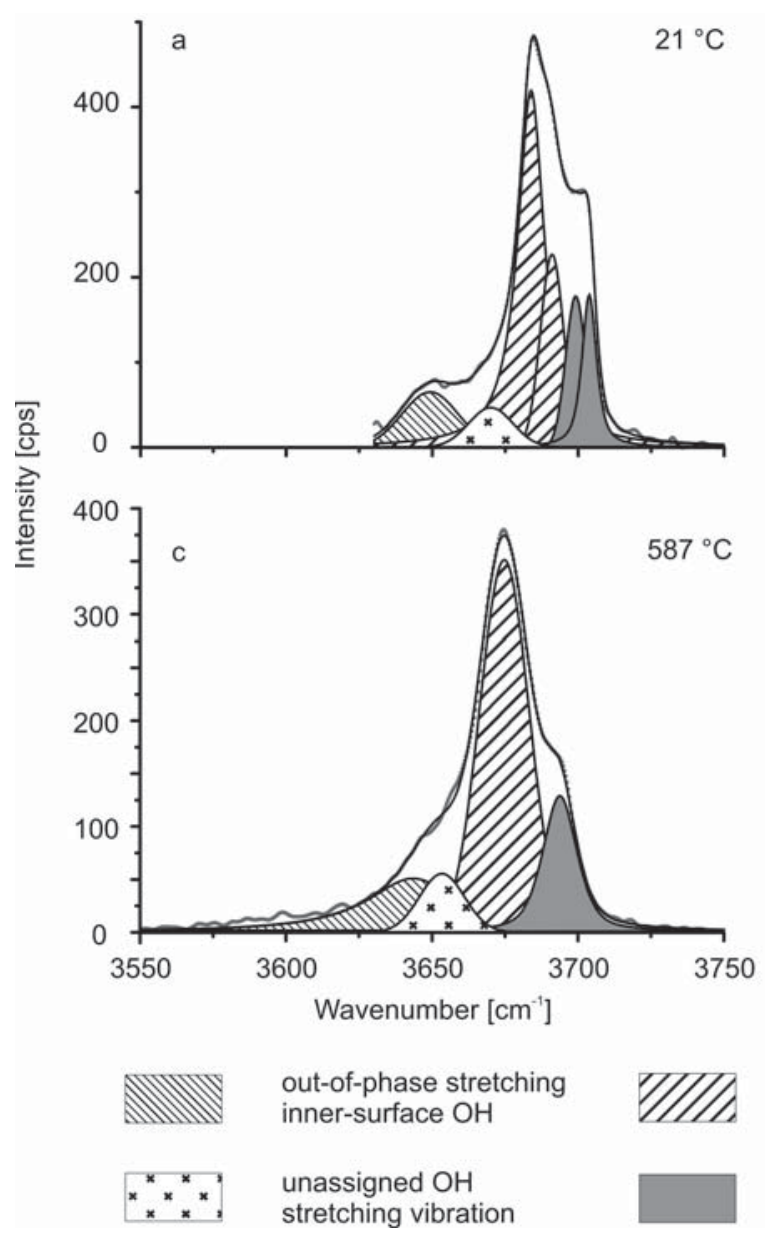

These bands are often situated at wavenumbers significantly different from that of initial $\mathrm{OH}$ bands. In the case of talc, such extra bands occur within the range of the primary $\mathrm{OH}$ bands (Zhang et al. 2006). In our experiments, the band at $3669 \mathrm{~cm}^{-1}$ (FTIR) and $3670 \mathrm{~cm}^{-1}$ (Raman), respectively, labeled as the unassigned band in Figure 3, can be interpreted as resulting from some non-structural $\mathrm{OH}$ species already present at RT, but increasing during dehydroxylation. A third possible cause for the additional bands may be the presence of different polytypes, turbostratic stacking faults or curved, chrysotile-like layers within the lizardite sample (Trittschack and Grobéty 2012). Defects have been suggested as an explanation for additional hydroxyl bands in amphiboles (Burns and Strens 1966), micas (Beran 2002), and kaolinite and dickite (Brindley et al. 1986). For samples containing more than one polymorph of a phase, individual frequency shift rates $(\delta v / \delta T)$ for specific modes of individual polymorphs may change the degree of overlap. This changes the number of bands necessary for an accurate fit of the measured spectra. Brindley et al. (1986) document such temperature-dependent $\mathrm{OH}$ band specific shifts in kaolinite and dickite. However, taking the possibility of a LO-TO splitting into account, such a solution is simplistic.

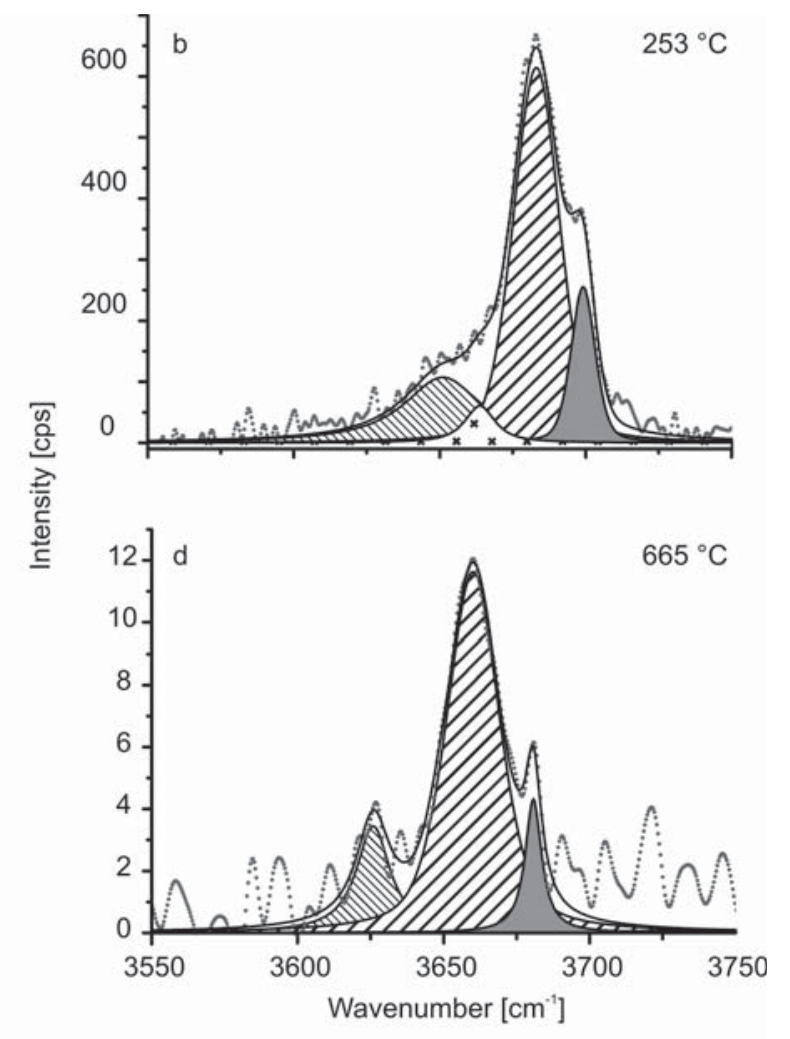

in-phase stretching inner-surface $\mathrm{OH}$

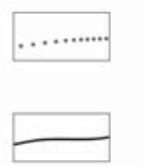

measured data

inner $\mathrm{OH}$ stretching

fitted data

FIGURE 7. (a-d) OH stretching frequency range of temperature-dependent Raman measurements representing significant intensity reduction between RT and $665^{\circ} \mathrm{C}$, the highest temperature where $\mathrm{OH}$ signals are still present. 


\section{The lizardite dehydroxylation I: Comparison between FTIR, Raman, and TGA data}

The temperature at which the absorbance of the $\mathrm{OH}$ bands starts to decrease in the FTIR spectra is comparable with the dehydroxylation onset observed in TGA analysis of the same sample (Trittschack and Grobéty 2012). The rate of the intensity decrease (Fig. 11) is, however, more rapid than the TGA derived dehydroxylation rates in experiments with comparable heating rate $\left(540{ }^{\circ} \mathrm{C}\right.$ compared to $\sim 650{ }^{\circ} \mathrm{C} \leq T_{\max } \leq \sim 720^{\circ} \mathrm{C}$ ) reported by Trittschack and Grobéty (2012). The explanation for the discrepancy may be that the two techniques monitor different steps of the dehydroxylation process. Whereas FTIR/Raman spectroscopy is sensitive to the primary hydrogen and hydroxyl liberation steps, TGA monitors the exit of the dehydroxylation products from the sample e.g., the weight loss after the products leaves the reactant grain and the powder. Thus, the TGA signal is initially delayed relative to the spectroscopic signal. The differences in dehydroxylation maxima observed in FTIR and Raman data are related to the different samples used. Also, the preparation of the samples used for the FTIR and Raman experiments were different: whereas for the Raman spectroscopy a gently pressed powder and a single crystal were used, the FTIR spectroscopy was obtained on a thin transparent film pressed in a DAC. The partial pressure (or activity) of the product species (water, hydroxyl, hydrogen, and/or oxygen molecules) along the diffusion path decreases more rapidly in a thin film than in a loose powder and single crystal, respectively. This increases the absolute dehydroxylation reaction rate in the thin film, which may explain the accelerated intensity loss observed in the FTIR measurements. A similar explanation has been suggested for the differences in IR spectra between annealed pyrophyllite samples of a varying thickness (Wang et al. 2002).

\section{The lizardite dehydroxylation II: Kinetic aspects and their spectroscopic indications}

The activation energy $E_{A}$ as function of the reaction progress estimated by TGA based dehydroxylation studies of lizardite shows an initial increase from 200 to over $350 \mathrm{~kJ} / \mathrm{mol}$ followed by a plateau (Trittschack and Grobéty 2012). For heating rates similar to the one used here, the activation energy plateau is reached at about $50{ }^{\circ} \mathrm{C}$ below the temperature at which the $\mathrm{OH}$ bands have lost almost $60 \%$ (at $639^{\circ} \mathrm{C}$ ), respectively, $98 \%$ (665
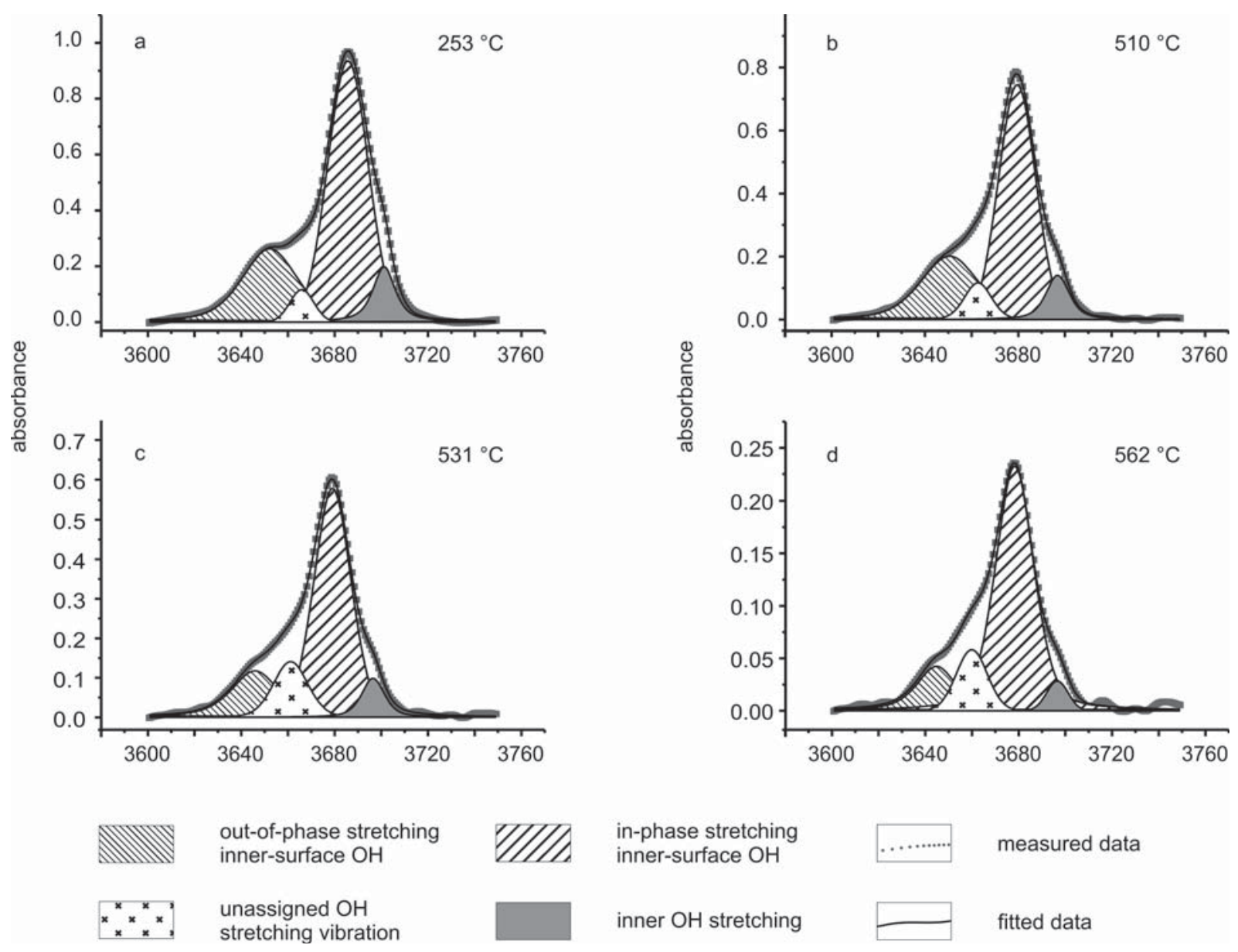

FIGURE 8. (a-d) OH stretching frequency range of temperature-dependent FTIR measurements representing a significant reduction in absorbance between RT and $562{ }^{\circ} \mathrm{C}$. 

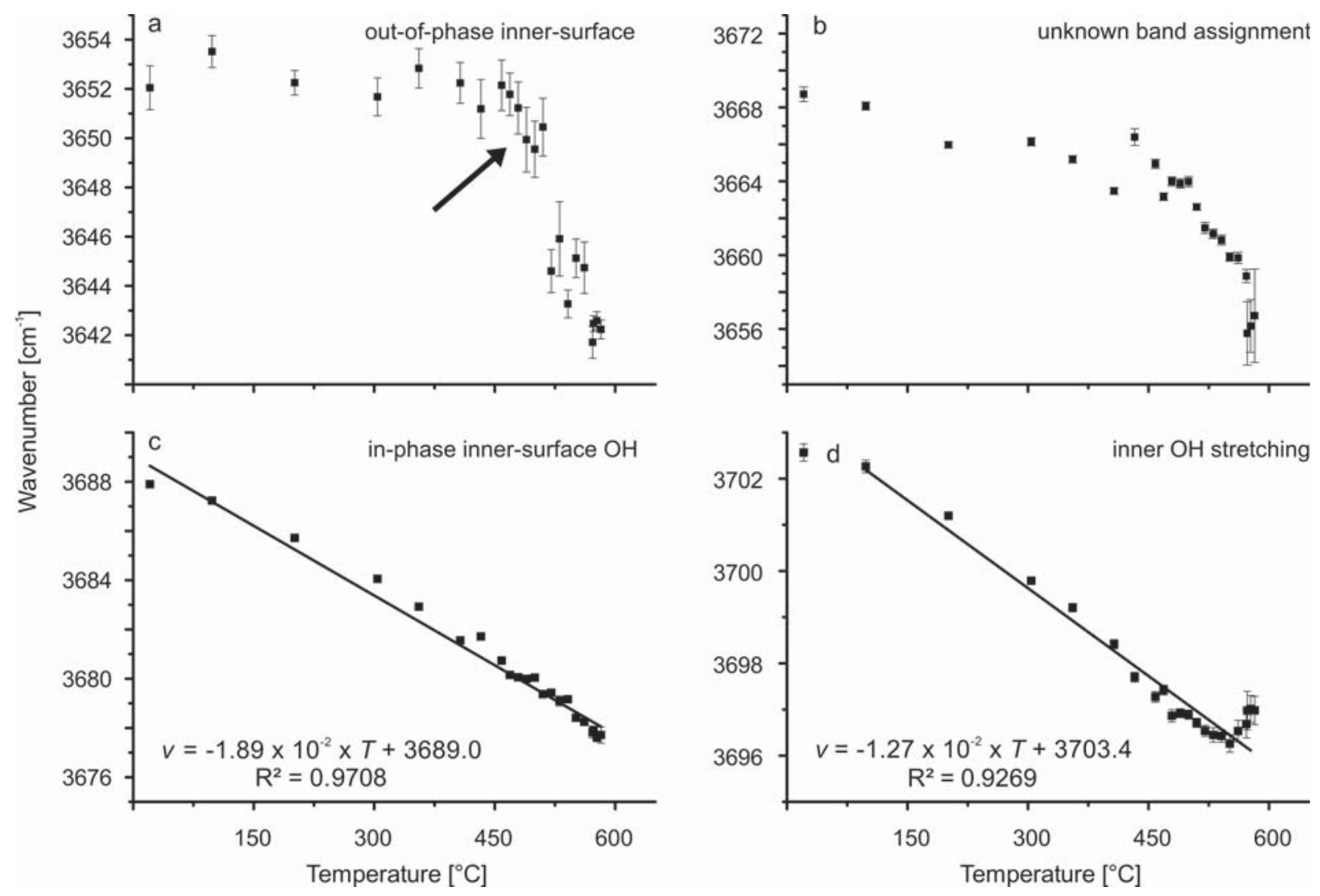

FIGURE 9. (a-d) Development of the inner and inner-surface IR OH stretching frequencies during heat treatment; error bars are illustrated and may be smaller than the shown data points.

${ }^{\circ} \mathrm{C}$ ) of their intensity in the Raman spectrum. DFT calculations and almost all previous works (e.g., Gualtieri and Ferrari 2006; Molina-Montes et al. 2008a, 2008b; Sperinck et al. 2011) propose a recombination of neighboring proton and hydroxyl ions to $\mathrm{H}_{2} \mathrm{O}$ molecules as the primary reaction step, followed by diffusion of the products $\left(\mathrm{H}_{2} \mathrm{O}\right.$ molecules $)$ along the interlayer to the surface. Several distinct recombination variants are possible, which differ by the distance between the reacting hydroxyls. Trittschack and Grobéty (2012) interpreted the increasing $E_{A}$ as a result of these parallel recombination steps, whereby the close distance, low $E_{A}$ recombination reactions occur at the beginning of dehydroxylation. With increasing reaction progress, longer distance recombination variants with higher $E_{A}$ become more frequent. The plateau $E_{A}$ corresponds to the recombination variant with the highest $E_{A}$ and the slight decrease indicates the increasing influence of transport in certain parts of the sample (large grains). This interpretation is compatible with DFT calculations (Molina-Montes et al. 2008a, 2008b; Sperinck et al. 2011), but not with experimental work by Gualtieri and Ferrari (2006) and Gualtieri et al. (2012), who indicate one-dimensional diffusion of $\mathrm{H}_{2} \mathrm{O}$ molecules through the six-membered silicate rings. In the latter case, $\mathrm{H}_{2} \mathrm{O}$-related modes should be visible in in situ Raman and FTIR spectra of partially dehydrated samples. Martin (1977) and Datta (1991) described a broad, infrared active band between 3200 and $3500 \mathrm{~cm}^{-1}$ in thermally pretreated chrysotile samples, which they assign to $\mathrm{H}_{2} \mathrm{O}$ modes. Such bands were not present in our spectra. Also Zhang et al. (2010) did not find any $\mathrm{H}_{2} \mathrm{O}$-related bands in their FTIR spectra of partially dehydrated sericite, muscovite, pyrophyllite, and talc. Zhang et al. (2005) prefer a hydrogen/oxygen/hydroxyl hopping mechanism over $\mathrm{H}_{2} \mathrm{O}$ molecule diffusion as the transport mechanism for the dehydroxylation products. The transport by hopping requires similar bond breaking and formation steps as the initial liberation reactions. The transport mechanism would have similar $E_{A}$ as the primary reactions, and could, therefore, also become ratelimiting. Thus, transport could also contribute to the $E_{A}$ plateau. The increased intensity of the unassigned $\mathrm{OH}$ mode during dehydroxylation in both the FTIR and Raman spectra may be related to such transient hydroxyl groups formed during transport. This interpretation is tentative, because the unassigned hydroxyl band is the result of the deconvolution of strongly overlapping bands.

\section{Dehydroxylation products: A talc-like intermediate and forsterite}

To approximately $450{ }^{\circ} \mathrm{C}$, the spectra are only affected by a constant frequency shift of the Raman and IR bands, which relate to thermal expansion of the structure. The intensity of all bands remains nearly constant to this temperature (Figs. 4 and 11a). Above this temperature, bands assigned to atom groups belonging to the octahedral sheet, i.e., $\mathrm{A}_{1 \mathrm{~g}}$ mode of lizardite (Fig. 6b) and $\mathrm{OH}$ stretching vibrations (Fig. 9a), show a strongly discontinuous behavior (Figs. 6b and 6f). This is interpreted as resulting from 
changes in the atomic bonding environment. These changes occur at about the same temperature where the absorbances/ intensities of the $\mathrm{OH}$ bands start to decrease. Thus, the onset of dehydroxylation affects only the octahedral sheet. The different behavior of the in-phase (Fig. 9a) and out-of-phase $\mathrm{OH}$ stretching mode frequencies (Fig. 9c) as function of temperature, however, is surprising. The in-phase stretching mode shows a break in the slope of $\delta v / \delta T$, whereas the slope of the out-of-phase mode is characterized by a linear slope. Modes originating from the same atomic group should show the same frequency behavior. A possible cause may be the deconvolution procedure.

The small temperature-dependent shift of the O-Si-O bending mode located at $129 \mathrm{~cm}^{-1}$ (RT) to lower wavenumbers is related to the change in ditrigonal distortion of the tetrahedral

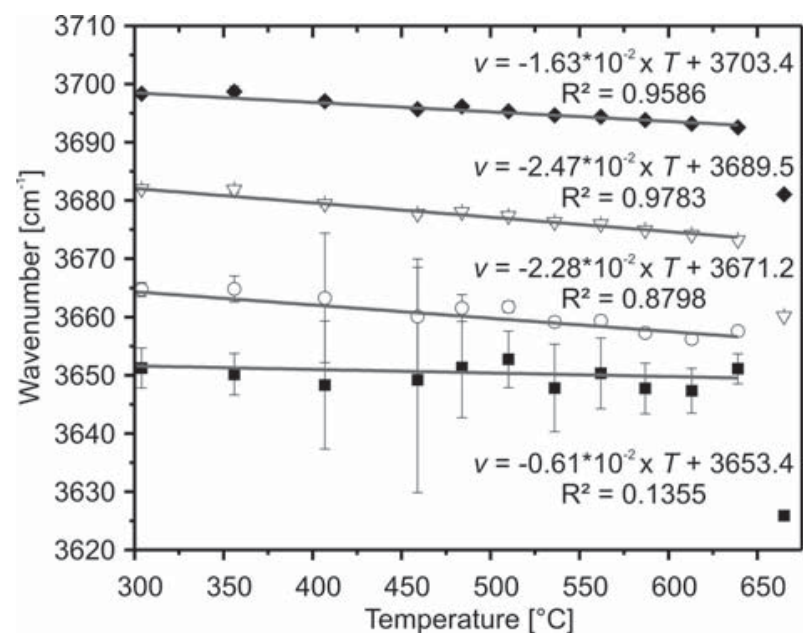

FIGURE 10. Development of the inner and inner-surface Raman $\mathrm{OH}$ stretching frequencies during heat treatment, error bars are illustrated and may be smaller than the shown data points; open circle = unassigned band, filled rhomb = inner $\mathrm{OH}$ band, filled square = out-of-phase innersurface $\mathrm{OH}$ band, reverse triangle = in-phase inner-surface $\mathrm{OH}$ band. sheet as demonstrated by X-ray diffraction (Guggenheim and Zhan 1998). The shifting rate $\delta v / \delta T$ is one order of magnitude smaller than for all other bands $\left(-0.439 \mathrm{~cm}^{-1} / 100{ }^{\circ} \mathrm{C}\right)$. The first intensity changes in Si-O-related Raman modes occur above $600{ }^{\circ} \mathrm{C}$ (Fig. 4) where the hydroxyl modes have lost more than half of their initial intensity (Fig. 12a). The tetrahedral sheet is thus not affected by the initial changes in the octahedral sheet. The large jump in frequency of the $\mathrm{A}_{1 \mathrm{~g}}$ mode of lizardite down to $183 \mathrm{~cm}^{-1}$ and the jump in frequency of the $\mathrm{v}_{\mathrm{s}} \mathrm{Si}-\mathrm{O}_{\mathrm{b}}$-Si band is assigned to product phase(s) of the dehydroxylation. Under ambient, dry conditions the first recognizable dehydroxylation product is mainly amorphous, but crystallizes upon further heating to forsterite, followed by enstatite (Brindley and Hayami 1963). The stable products of the dehydroxylation reaction of pure magnesian lizardite under hydrothermal conditions are talc, forsterite, and water (O’Hanley et al. 1989). Various authors (e.g., McKelvy et al. 2004; Brindley and Zussman 1957) reported low-angle peaks in X-ray diffractograms of thermally treated serpentine phases, indicating that amorphization is not complete and that dehydroxylation produces intermediate partially ordered structures. Although differing in detail, early studies by Ball and Taylor (1963) and Brindley and Hayami (1965) proposed reaction sequences with disordered dehydroxylated intermediates. They infer the presence of a partially ordered structure from the topotactic relationship between forsterite and serpentine (Brindley and Hayami 1963). Based on a peak corresponding to a $d$-spacing of $14 \AA$, McKelvy et al. (2006) proposed the formation of a lamellar oxyhydroxide meta-serpentine characterized by a doubled cell dimension along the $c$ axis and a heterogeneous $\mathrm{OH}$ distribution. Their DFT calculations support the formation of such a $14 \AA$ structure, which is transformed to an amorphous phase with progressive dehydroxylation. Two different partially ordered, anhydrous intermediates, dehydroxylate I and II, are proposed by MacKenzie and Meinhold (1994) based on ${ }^{25} \mathrm{Mg}$ and ${ }^{29} \mathrm{Si}$ shifts in NMR spectra of heated chrysotile samples. According to these authors, dehydroxylate I has a structure similar to the parent phase, whereas the ${ }^{29} \mathrm{Si}$ NMR position of dehydroxylate II is similar to talc. Viti (2010) suggests the formation of intermedi-
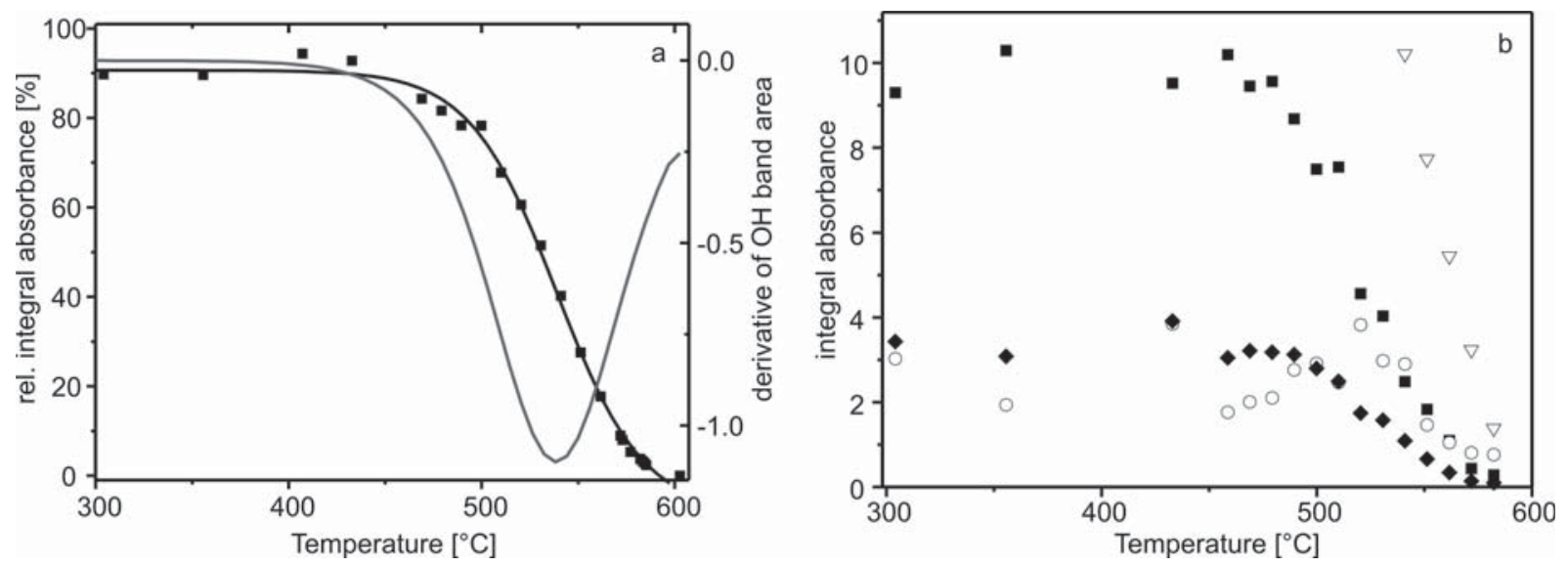

FIGURE 11. (a) Decrease of the integrated absorbance of all FTIR OH stretching bands as function of temperature and corresponding derivative curve and (b) for the individual inner-surface $\mathrm{OH}$ stretching bands and the unassigned band. The course of the inner OH stretching band behaves like the inner-surface $\mathrm{OH}$ bands and is just shown for temperatures higher than $500{ }^{\circ} \mathrm{C}$. All symbols have the identical assignment as in Figure 10 . 

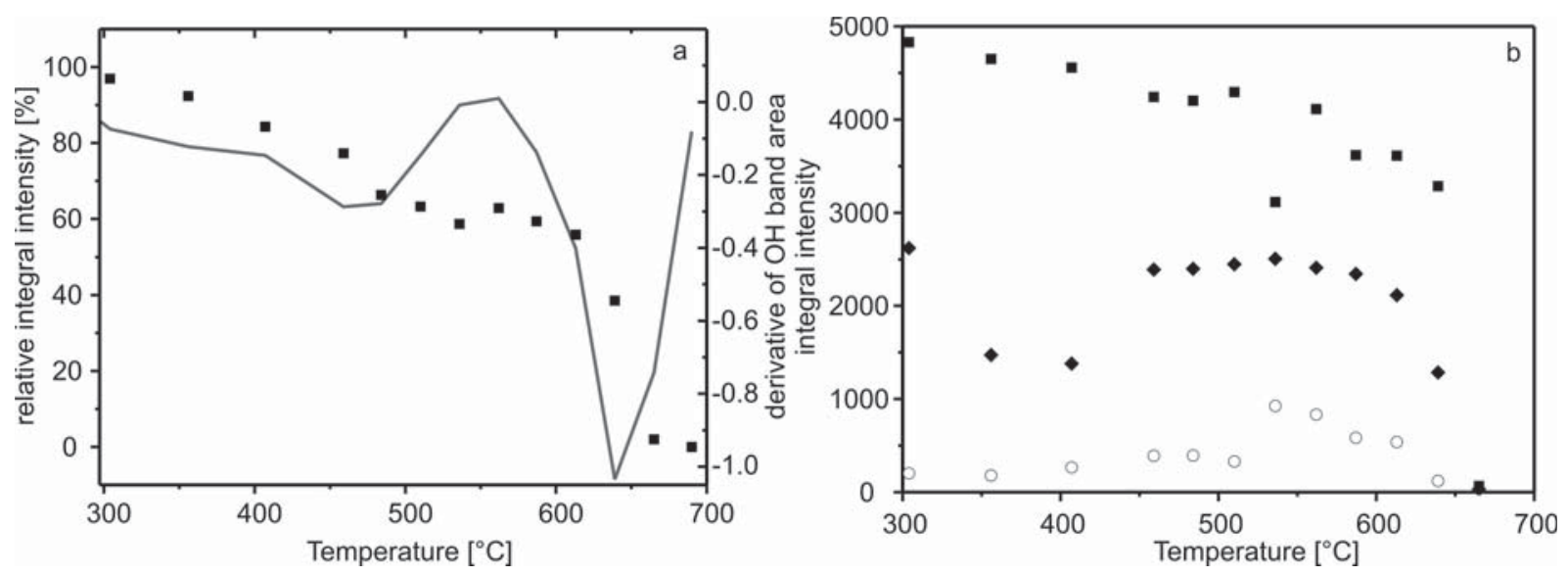

FigURE 12. (a) Decrease of the integrated intensity of all Raman $\mathrm{OH}$ stretching bands as function of temperature and corresponding derivative curve and (b) for the individual inner-surface $\mathrm{OH}$ stretching bands and the unassigned band. All symbols have the identical assignment as in Figure 10 .

ate, partially ordered dehydroxylation products on the bases of DTG/DTA analyses of lizardite. Their weight-loss rate curves show two maxima, a feature also observable in DTG experiments of Trittschack and Grobéty (2012). The first maximum is attributed to the partial dehydroxylation of the initial lizardite leading to the intermediate phase. The dehydroxylation of the latter would be responsible for the second maximum.

Three new features at 183,350 , and $670 \mathrm{~cm}^{-1}$ in the spectrum at $665^{\circ} \mathrm{C}$, which cannot be assigned to either lizardite or forsterite, are interpreted as originating from one or more intermediate phases. Supported by a band appearing at $1000 \mathrm{~cm}^{-1}\left(690{ }^{\circ} \mathrm{C}\right)$ it is possible to assign them as Raman bands related to talc as reported by Fumagalli et al. (2001). The bands located at 670 and $1000 \mathrm{~cm}^{-1}$ are also observable in the spectrum of the quenched dehydroxylated sample, where they are shifted to 686 and 1021 $\mathrm{cm}^{-1}$, respectively. Referring to Fumagalli et al. (2001) these bands can be assigned to a $\mathrm{Mg}(\mathrm{O}, \mathrm{OH})_{6}$ mode $\left(183 \mathrm{~cm}^{-1}\right)$, a symmetric $\mathrm{SiO}_{4}$ mode $\left(350 \mathrm{~cm}^{-1}\right)$, a $v_{\mathrm{s}} \mathrm{Si}-\mathrm{O}_{\mathrm{b}}-\mathrm{Si}$ mode in case of the $670 \mathrm{~cm}^{-1}\left(686 \mathrm{~cm}^{-1}\right.$ at RT) feature (Fig. 5d) and one Si-O stretching mode represented by the $1000 \mathrm{~cm}^{-1}$ feature at $819{ }^{\circ} \mathrm{C}$ and $1021 \mathrm{~cm}^{-1}$, respectively, in the spectra of the quenched sample. The strongest of three weak single bands in the $\mathrm{OH}$ stretching mode region (Fig. 7d) is also consistent with the spectrum of talc (Fumagalli et al. 2001). This interpretation supports NMR observations by MacKenzie and Meinhold (1994) who proposed a talc-like structure for their dehydroxylate II phase. During dehydroxylation, the partial pressure of the volatile products may be sufficiently high in certain regions of the sample to nucleate talc, a stable product of the lizardite dehydroxylation in the hydrous system (O’Hanley et al. 1989). The band at $183 \mathrm{~cm}^{-1}$ appears also in the dehydroxylation of chrysotile (Trittschack and Grobéty, unpublished manuscript), where it is present for a much broader temperature range.

\section{ACKNOWLEDGMENTS}

The authors thank S. Guggenheim, one anonymous reviewer, and the associate editor Richard Yuretich for their helpful comments and suggestions to improve the manuscript. Special thanks goes to S. Speziale for his Raman support, M. Mellini for providing the Monte Fico sample, and E. Libowitzky for some general discussions concerning the spectral data. This study was funded by the Swiss National Science Foundation (grant 200021-121964).

\section{REFERENCES CITED}

Auzende, A.-L., Daniel, I., Reynard, B., Lemaire, C., and Guyot, F. (2004) Highpressure behaviour of serpentine minerals: a Raman spectroscopic study. Physics and Chemistry of Minerals, 31, 269-277.

Balan, E., Saitta, A.M., Mauri, F., Lemaire, C., and Guyot, F. (2002) First-principles calculation of the infrared spectrum of lizardite. American Mineralogist, 87, 1286-1290.

Ball, M.C. and Taylor, H.F.W. (1963) The dehydration of chrysotile in air and under hydrothermal conditions. Mineralogical Magazine, 33, 467-482.

Beran, A. (2002) Infrared spectroscopy of micas. In A. Mottana, F.P. Sassi, J.B. Thompson, Jr., and S. Guggenheim, Eds., Micas: Crystal Chemistry and Metamorphic Petrology, 46, 351-369. Reviews in Mineralogy and Geochemistry, Mineralogical Society of America, Chantilly, Virginia.

Brindley, G.W. and Hayami, R. (1963) Kinetics and mechanisms of dehydration and recrystallization of serpentine-1. Clays and Clay Minerals, 12, 35-47. (1965) Mechanism of formation of forsterite and enstatite from serpentine. Mineralogical Magazine, 35, 189-195.

Brindley, G.W. and Zussman, J. (1957) A structural study of the thermal transformation of serpentine minerals to forsterite. American Mineralogist, 42, 461-474.

Brindley, G.W., Chih-Chun, K., Harrison, J.L., Lipsicas, M., and Raythatha, R. (1986) Relation between structural disorder and other characteristics of kaolinites and dickites. Clays and Clay Minerals, 34, 239-249.

Burns, R.G. and Strens, R.G.J. (1966) Infrared study of the hydroxyl bands in clinoamphiboles. Science, 153, 890-892.

Datta, A.K. (1991) Dehydration of chrysotile asbestos-an infrared-absorption study. Journal of Materials Science Letters, 10, 870-871.

Farmer, V.C. (1974) The layer silicates. In V.C. Farmer, Ed., The Infrared Spectra of Minerals, p. 331-363. Mineralogical Society, London. (1998) Differing effects of particle size and shape in the infrared and Raman spectra of kaolinite. Clay Minerals, 33, 601-604.

Fuchs, Y., Linares, J., and Mellini, M. (1998) Mössbauer and infrared spectrometry of lizardite-1T from Monte Fico, Elba. Physics and Chemistry of Minerals, 26, 111-115.

Fumagalli, P., Stixrude, L., Poli, S., and Snyder, D. (2001) The $10 \AA$ phase: a high-pressure expandable sheet silicate stable during subduction of hydrated lithosphere. Earth and Planetary Science Letters, 186, 125-141.

Gillet, P. (1996) Raman spectroscopy at high pressure and high temperature. Phase transitions and thermodynamic properties of minerals. Physics and Chemistry of Minerals, 23, 263-275.

Gualtieri, A.F. and Ferrari, S. (2006) Kinetics of illite dehydroxylation. Physics and Chemistry of Minerals, 33, 490-501.

Gualtieri, A.F., Giacobbe, C., and Viti, C. (2012) The dehydroxylation of serpentine group minerals. American Mineralogist, 97, 666-680.

Guggenheim, S. and Zhan, W. (1998) Effect of temperature on the structures of lizardite- $1 T$ and lizardite- $2 H_{1}$. Canadian Mineralogist, 36, 1587-1594.

Guggenheim, S., Chang, Y.-H., and Koster van Gross, A.F. (1987) Muscovite dehydroxylation: high-temperature studies. American Mineralogist, 72, 537-550.

Kloprogge, J.T., Frost, R.L., and Rintoul, L. (1999) Single crystal Raman microscopic study of the asbestos mineral chrysotile. Physical Chemistry Chemical Physics, 1, 2559-2564.

Libowitzky, E. (1999) Correlation of O-H stretching frequencies and O-H $\cdots$ O hydrogen bond lengths in minerals. Monatshefte für Chemie, 130, 1047-1059. 
MacKenzie, K.J.D. and Meinhold, R.H. (1994) Thermal reactions of chrysotile revisited: ${ }^{29} \mathrm{Si}$ and ${ }^{25} \mathrm{Mg}$ MAS NMR study. American Mineralogist, 79, 43-50.

Martin, C.J. (1977) The thermal decomposition of chrysotile. Mineralogical Magazine, 41, 453-459.

McKelvy, M.J., Chizmeshya, A.V.G., Diefenbacher, J., Béarat, H., and Wolf, G. (2004) Exploration of the role of heat activation in enhancing serpentine carbon sequestration reactions. Environmental Science and Technology, 38, 6897-6903.

McKelvy, M.J., Sharma, R., and Chizmeshya, A.V.G. (2006) Lamellar reaction phenomena: from intercalation to nanomaterials formation. Journal of Physics and Chemistry of Solids, 67, 888-895.

McKeown, D.A., Bell, M.I., and Caracas, R. (2010) Theoretical determination of the Raman spectra of single-crystal forsterite $\left(\mathrm{Mg}_{2} \mathrm{SiO}_{4}\right)$. American Mineralogist, 95, 980-986.

Mellini, M. (1982) The crystal structure of lizardite 1T: hydrogen bonds and polytypism. American Mineralogist, 67, 587-598.

Mellini, M. and Viti, C. (1994) Crystal-structure of lizardite-1T from Elba, Italy. American Mineralogist, 79, 1194-1198.

Molina-Montes, E., Donadio, D., Hernández-Laguna, A., Sainz-Díaz, C.I., and Parrinello, M. (2008a) DFT research on the dehydroxylation reaction of pyrophyllite 1 . First-principle molecular dynamics simulations. Journal of Physical Chemistry B, 112, 7051-7060.

Molina-Montes, E., Donadio, D., Hernández-Laguna, A., and Sainz-Díaz, C.I. (2008b) DFT research on the dehydroxylation reaction of pyrophyllite- 2 . Characterization of reactants, intermediates, and transition states along the reaction path. Journal of Physical Chemistry A, 112, 6373-6383.

O’Hanley, D.S., Chernosky, J.V., and Wicks, F.J. (1989) The stability of lizardite and chrysotile. Canadian Mineralogist, 27, 483-493.

Prencipe, M., Noel, Y., Bruno, M., and Dovesi, R. (2009) The vibrational spectrum of lizardite- $1 T\left[\mathrm{Mg}_{3} \mathrm{Si}_{2} \mathrm{O}_{5}(\mathrm{OH})_{4}\right]$ at the $\Gamma$ point: a contribution from an ab initio periodic B3LYP calculation. American Mineralogist, 94, 986-994.

Rinaudo, C. Gastaldi, D., and Belluso, E. (2003) Characterization of chrysotile, antigorite and lizardite by FT-Raman spectroscopy. Canadian Mineralogist, 41, 883-890.

Sperinck, S., Raiteri, P., Marks, N., and Wright, K. (2011) Dehydroxylation of kaolinite to metakaolin-A molecular dynamics study. Journal of Materials Chemistry, 21, 2118-2125.

Trittschack, R. and Grobéty, B. (2012) Dehydroxylation kinetics of lizardite. European Journal of Mineralogy, 24, 47-57.

Viti, C. (2010) Serpentine minerals discrimination by thermal analysis. American Mineralogist, 95, 631-638.

Wang, L., Zhang, M., Redfern, S.A.T., and Zhang, Z. (2002) Dehydroxylation and transformation of the 2:1 phyllosilicate pyrophyllite at elevated temperatures: an infrared spectroscopic study. Clays and Clay Minerals, 50, 272-283.

Zhang, M., Wang, L., Hirai, S., Redfern, S.A.T., and Salje, E.K.H. (2005) Dehydroxylation and $\mathrm{CO}_{2}$ incorporation in annealed mica (sericite): An infrared spectroscopic study. American Mineralogist, 90, 173-180.

Zhang, M., Hui, Q., Lou, X.-J., Redfern, S.A.T., Salje, E.K.H., and Tarantino, S.C. (2006) Dehydroxylation, proton migration, and structural changes in heated talc: An infrared spectroscopy study. American Mineralogist, 91, 816-825.

Zhang, M., Redfern, S.A.T., Salje, E.K.H., Carpenter, M.A., and Wang, L. (2010) $\mathrm{H}_{2} \mathrm{O}$ and the dehydroxylation of phyllosilicates: An infrared spectroscopic study. American Mineralogist, 95, 1686-1693. 